\title{
Role of Radio in Improving Livelihoods: The Case of Central Broadcasting Services' Project to Empower Women in Savings and Loan Associations in Nsangi Sub-County, Wakiso District, Uganda
}

\section{Margaret B, Nangooba ${ }^{1}$}

CUganda Martyrs University

\begin{abstract}
This study investigated Central Broadcasting Services' Project to Empower Women in Savings and Loan Associations (CBS-PEWOSA) in Nsangi sub-county, Wakiso district, Uganda. Data was gathered from members of the associations using questionnaires, key informant interviews and focus group discussions. The findings showed that the project has increased awareness about and knowledge of solutions to community development problems ranging from culture, rural development, education, and women empowerment to agriculture. Communities have been mobilized to form groups, save and borrow to invest in Small and Medium Enterprises, which has led to improvements in their livelihoods. However, illiteracy, resistance to new ideas, under funding and limited airtime allocated to development programs on the radio are constraining the project. Recommendations for the improved effectiveness of the project are made.
\end{abstract}

Keywords Media; Radio; CBS PEWOSA; Livelihoods

\section{Le Rôle des Médiasdansl'Amélioration des moyens de Subsistance: un Cas de CBS PEWOSA.}

\section{Résumé}

cetteétude a examiné le rôle des medias dansl'amélioration des moyens de subsistance des membres des services de radiodiffusioncentraux - projetvisant à autonomiser les femmes dans les Associations D'épargne et de prêt (CBS PEWOSA) dans le sous-Comté de Nsangi, district de Wakiso,

\footnotetext{
${ }^{1}$ Uganda Martyrs University, nangom2004@gmail.com
} 
Ouganda. Les donnéesontétérecueilliesauprès du personnel et des membres du PEWOSA et de la SCS à l'aide de questionnaires, d'entrevues avec des informateursclés et de Discussions de groupe. Il enestressorti que CBS radio, dans le cadre de son projet PEWOSA, a amélioré la sensibilisation et la connaissance des solutions aux problèmes de développementcommunautaire, qu'ils'agisse de la culture, du développement rural, de l'éducation, de l'autonomisation des femmes ou de l'agriculture. Par L'entremise de CBS radio, les collectivitéssontmobilisées pour former des groupes, épargner et emprunter de l'argentqu'ellesinvestissentdans les petites et moyennesentreprises (PME) afind'améliorerleursmoyens de subsistance. Toutefois, les niveauxélevésd'analphabétisme du public visé, la résistance aux idéesnouvelles et aux innovations, sous le financement du projet PEWOSA et le peu de temps alloué aux programmes de développement à la radio, entravent la miseenœuvre effective de CBS PEWOSA. Par conséquent, ilestrecommandé que les commentairesréguliers des membressoientessentiels au maintien du projet.Motsclés:médias, CBS radio, CBS PEWOSA, moyens de subsistence.

\section{Introduction}

According to Turow (2016), development communication refers to the use of communication to facilitate social development. Development communication engages stakeholders and policy makers, establishes conducive environments, assesses risks and opportunities, and promotes information exchanges to bring about positive social change. Development communication techniques include information dissemination and education, social marketing, social mobilization, media advocacy, communication for social change and community participation. Nora (1975, p. 198) defined development communication as the art and science of human communication applied to the speedy transformation of a country from poverty to a dynamic state of economic growth and makes possible greater economic and social equality and the larger fulfillment of human potential.

Radio plays a very significant role in the development of communities in both rural and urban areas. As issues of development are aired, listeners are exposed to what is happening in and around their society. Velentzas (2014) describes radio information as a pool of ideas that strengthen the feeling of togetherness through the exchange of messages which translate thoughts into actions. Radio programmes educate people on new issues affecting them especially in the areas of politics, business, current affairs, agriculture and others, which create awareness and action among listeners. Radio remains one of the most cost-effective means of building awareness, and supporting the adoption of new farming practices by small scale farmers for sustainable development in agriculture (Nabusoba, 2014; Guenthner and Swan, 2011). It is appropriate for creating general awareness and bringing desirable changes in the attitude of listeners. Radio plays a significant role for farmers in gathering information on various kinds of agricultural activities so as to update their knowledge and skills (Chapota et al, 2014). There are clear incentives for commercial radio in a competitive environment to be responsive to the demands and interests of mass audiences.

Girard (2003) indicates that by 1988, there were only ten independent (non-State) radios in Sub-Saharan Africa. Since then, radio has been developing because of cheap transistors and the inability of television to compete favorably due to high unit costs, lack of rural electrification and the opening-up of the airwaves in many countries. The new investments in this direction are partly attributed to the fact that radios have a catalytical potential for development, particularly when it comes to community and local based radios (Gumucio, 2001). Since the turn of the millennium, there has been an explosion in the numbers of small radio stations all over Africa (Myers, 2009). The BBC AMDI research across 17 subSaharan countries found that local commercial radios grew by an average of 360 percent between 2000 and 2006 and that community radio had grown on average by a striking 1,386 percent over the same period. 
In Uganda, greater relevance to small businesses was achieved through the use of local languages on radios that are responsive to people's issues and interests. Anderson et al, (2007) argues that without a competitive industry with corresponding regulations and supporting functions, there would be no innovations in programming especially when it comes to investigative and local current affairs shows. Therefore, the use of local languages creates a competitive environment to attract listenership.

Over 300 radio stations are registered in Uganda. In 2015, 292 FM stations were operational (UCC, 2015, p. 9). However, many of these stations are restricted to certain geographical areas, so listenership is fragmented. The Uganda Media Measurement report found that even the leading station, Capital FM, only had an average 10 percent of the audience share. Central Broadcasting Service (CBS FM), also known as Radio Buganda, has an average share of 4.5 percent (Uganda Q3, 2016). The radio was opened on 22 June, 1996, with an aim of helping build society by example and participation, while balancing entertainment and development issues. In Buganda, CBS FM is considered as one of the most important resources in promoting agriculture and rural development because it assists farmers to take decisions and appropriate actions for further development. According to the radio's Strategic Plan (2010 - 2014), CBS does not only engage in broadcasting services but has also over the years initiated several social economic programs aimed at uplifting its listeners' livelihoods.

CBS's major socio-economic objectives are; a) to mobilize the population for social and economic development; and b) to educate, entertain and sensitize the public on ways of improving their livelihood. These objectives led to the birth of several social action programs that among others include, the Project to Empower Women in Savings and Loan Associations (PEWOSA), to empower people in Buganda towards achieving wealth through wealth creation programs. At its establishment, CBS PEWOSA was majorly targeting women because of the long history of being marginalized, deprivation on one hand and on the other because of the proven discipline when it comes to financial matters and investment culture that is more family friendly. Under the project, communities are mobilized to form groups, save and borrow to invest in profit generating activities (CBS PEWOSA project write up 2009). PEWOSA's vision is: A dynamic organization promoting self- sufficiency and sustainable community developmental initiatives. Its Mission is, to empower wealth creation through propagation of people friendly saving, credit and investment models to the active poor.

This study investigated the role of radio in improving livelihoods among members of the project in Nsangi sub-county, Wakiso district in Uganda. The study was premised on the fact that although CBS radio was established in 1996 to mobilize the population for social and economic development hitherto, the radio's contribution towards improving its listeners' livelihoods had not been published in literature on development. The specific objectives of the study were to explore the effect of the radio's programs on the livelihoods of members of PEWOSA; and to compare the use of various CBS radio edutainment programmes in the improvement of education and exchange of ideas among members of PEWOSA.

The study was anchored on both the development media theory and the livelihood improvement approach. It concentrated on the evolution of the development media in general while the rest of the theoretical background explored the livelihood improvement approach in developing countries. The development media theory was formulated by McQuail (1987). This theory seeks to explain the normative behavior of the press in countries that are conventionally classified together as developing countries. This theory is opposed to dependency and foreign domination and to arbitrary authoritarianism. It accepts economic development and nation building as overriding objectives. The theory holds that the media has a role to play in facilitating the process of development in the developing countries. According to the development media theory, the media is used to serve the general good of the nation. The media is seen as agent of development and social change in any community. Thus, the theory is relevant to the study because it lays emphasis on using the media to develop society. 
Development media theory applies very well to the study especially in this new era of development communication where social media has been used extensively by a number of media houses and companies to get insights into what users or listeners think about their products and services. Nevertheless, an increasingly important requirement has been expressed by enterprises to go past the listening mode and actively engage with the users' conversations in real time, and directly on the various Social Media platforms. Towards this pursuit, enterprises have started to set-up their websites on popular social media channels such as, Facebook, YouTube and twitter, called 'brand pages'. Brand pages help enterprises capture relevant discussions among listeners and provide an opportunity to engage with them for instant feedback. Baird and Parasnis (2011) confirmed that the speed at which Social Media is being adopted by consumers of information is high.

Since the models of development communication are closely related to the human approaches to development, the study also explored the livelihood improvement approach. According to the JICA Tsukuba report of 2007, the livelihood improvement approach is a technique that was developed to improve the lives of people in rural Japan particularly in the late 1940s and 1950s before the nation entered its period of high economic growth. The farming sector in Japan had the same sorts of problems that many developing countries face today in areas such as daily living, sanitation and health. Under this approach, the problems that needed to be solved were identified, and the rural residents took possession of the activities to devise and implement solutions. An important characteristic of the livelihood improvement approach is its way of solving issues not by introducing foreign systems and technologies, but by skillfully using the limited resources available to improve people's lives (Toru, 2001). The livelihood improvement approach applies to the study because it was employed to solve rural and social development issues that are similar to those faced by Ugandans today.

Chambers and Conway (1991, p.6) proposed the following composite definition of a sustainable rural livelihood, which is applied most commonly at the household level: A livelihood comprises the capabilities, assets (stores, resources, claims and access) and activities required for a means of living. A livelihood is sustainable if it can cope with and recover from stress and shocks, maintain or enhance its capabilities and assets, and provide sustainable livelihood opportunities for the next generation. It should also contribute net benefits to other livelihoods at the local and global levels, in the short and long term.

\section{Methodology}

The study used mixed methods to collect and analyze primary and secondary data. It was carried out in the ten parishes that constitute Nsangi Sub County, Wakiso District. The Sub County was selected because this is where the project began (CBS PEWOSA Project Write Up, 2009). A sample of 100 project beneficiaries was selected from a population of 156. This was done using clustered random sampling (to draw ten beneficiaries from each of the ten parishes in Nsangi Sub County) and the project membership register as a sampling frame. These beneficiaries responded to a questionnaire and participated in group discussions (of six to ten participants), to expound on their responses. Additionally, questionnaires were administered to 50 members of the project who were drawn from the project's annual trade fair of 2019. Finally, key informant interviews were conducted with six senior staff of CBS Radio who are linked to PEWOSA. The responses to the questionnaires were analyzed using frequency counts and percentages. The interviewees' and group discussants' responses were transcribed. Thereafter, the transcripts were subjected to content analysis.

\section{Findings and Discussion}

The first objective of this study was to explore whether CBS radio programmes have had an effect on the livelihoods of members of PEWOSA. The radio's Programmes Director explained that the radio dedicates $60 \%$ of its airtime to development programmes with an aim of transforming society through cultural, social and economic programmes. Majority (91.3\%) of the respondents "strongly agreed" that this is the 
case. A key inference here is that the radio can, therefore, be used to pass on vital information as regards attitude, behaviour, knowledge, techniques and skills, which are expected to educate CBS PEWOSA members on issues of importance. This rhymes well with Asemah (2011) who notes that of the mass media generally available to Africans, radio is the most widespread and accessible. And because of its special qualities, radio can be a major force in bringing about development and, subsequently, quantitative and qualitative improvements in people's lives (Curran, 2000; Saidou, 2002). For instance, one of the CBS PEWOSA beneficiaries said in one of the focus group discussions in Kyengera parish that;

I was able to know about CBS PEWOSA because of listening to CBS Radio and I'm so grateful to this. I would not have owned a plot and been able to boost my business, you see PEWOSA groups give you a chance to network and have constructive friends who help you to progress. In times of success or grief you have colleagues by your side. We are really grateful to CBS and Stromme for the Project that has changed our lives (Interview with Kuteesa Robinah, Kyengera, 2019).

As far as the knowledge levels of presenters are concerned, respondents affirmed that presenters of development programmes are knowledgeable enough. The station engages experts or resource persons as guests on these programmes who are able to explain and make clear issues in their areas of expertise. This is in line with the views of Seidu et al (2011) that effective radio activities can make a significant change in a community's life. It was established that CBS listeners are given a number of platforms to share their views and give feedback about the particular radio programmes. For example, during the radio talk shows, listeners are given chance to call in and discuss about a given topic or theme as well as ask questions. This is in agreement with Curran, (2002) who stated that media can enable society to see itself in an idealized way, or involve the celebration of a shared value, memory or experience. During the study, $80.7 \%$ of the respondents strongly agreed that they have greatly benefited from the CBS PEWOSA project.

One member of CBS PEWOSA, who is also the Chairperson of ToliMwavu (You are not Poor) CMMF Group B in Nsangi, had this to say;

In 2014 my sister who resided three villages away from here had joined a CBS PEWOSA CMMF group and because she had already realized some benefits, she attracted me to join and start saving. It was after a while, that I joined Tolimwavu CMMF group in Nabbingo which was about 4 miles away from where I stay. The distance was long for me to travel on a weekly basis, so after one year I mobilized residents at my village and we formed a group of 24 members and named it after the first one (Tolimwavu CMMF group B) which is currently six years old.

I and my husband now own Food Umbrella; a spices and beverage Enterprise run as a small cottage at home, which processes a range of spices; Majani mix, Soya Tea, Tea Masala, Ginger, Cinnamon, Pillawo Masala, Beaf Masala, Chicken Masala, Mixed Spices, Garlic, Chia Seeds, Hibiscus, Rosemary, Coffee Powder and Tumeric. This business has greatly changed our lives for the better (Interview with Nampijja Victoria, Nsangi, 2019).

However, although the Programme Line up for CBS FM radio showed a distribution of $60 \%$ allocated to development programmes, the views from the majority of the respondents contradicted with the official time allocation of the radio station. It is therefore, important for the management to reconsider increasing on the time allocated to development programmes. Dhanraj, (2015) argues that promoting awareness of issues, protecting cultural diversity of communities and motivating them to participate in the planned development programmes can be enhanced effectively on a mass level through the community radio. 
Under the second research question, the study examined the role that CBS radio mobilisation plays in improving livelihood of members of PEWOSA. It was established that CBS radio has played a very big part in improving people's livelihoods through mobilizing its listeners. The CBS FM radio Strategic Plan (2010 - 2014) indicates that CBS radio was established with objectives not only for entertainment but mainly to mobilize the populace for social and economic development as well as to educate, entertain and inform the public on how to improve their livelihoods. Findings indicated that the objectives have been achieved through implementing projects among the rural active poor to improve livelihoods through both financial and non-financial empowerments. Respondents strongly agreed (72\%) that CBS radio has done a lot to empower their SACCO activities. CBS FM established an independent support organization to implement poverty elimination projects which aim at social mobilization to enhance livelihoods and employment generation opportunities of the poor. Self-managed grassroots institutions have been federated at parish and sub-county level groups (SACCOs) where communities are mobilized to form groups, save and access loans.

According to the CBS PEWOSA Monitoring and Evaluation database (2017), the value of savings among CBS PEWOSA members, amounts to Uganda shillings 3.375 billion with a cumulative loan fund of Uganda shillings 5 billion. CBS-PEWOSA has reached a phase of linking the formed savings and credit groups to bigger financial and other development services. As a result, the project has initiated a financial institution which has been registered in the name of CBS PEWOSA NsindikaNjakeEyeterekera (Financial Empowerment Through Savings) Cooperative Society Limited and CBS PEWOSA NsindikaNjake Network Market. The participatory methodology employed by the project leadership to identify members has been very effective in promoting community based programmes because of the constant interactions among group members. This in the end leads to a high level of ownership of the project outcomes in case of success or failure.

The Managing Director of CBS radio noted that;

CBS FM established CBS PEWOSA to implement poverty alleviation projects which aim at social mobilization to enhance livelihoods and employment generation opportunities of the poor. Self-managed grassroots institutions have been federated [into SACCOs] at parish and sub-county level (Interview with Kawooya Mwebe, Bulange-Mengo, 2019).

However, in one of the key informant interviews, the CMMF Officer for Nsangi sub-county highlighted some of the challenges faced in mobilizing people to be part of the PEWOSA project;

There is resistance of people to join because of fear that they will lose their savings. Some people join expecting free money. We also face challenges like disintegration of groups, illiteracy of the targeted people, fraud among some group members where some members connive to steal group funds and underfunding, as Stromme Foundation is the only funder of our Project since its inception (Lukwago Richard, Masengere - Mengo, 2019).

He also mentioned other challenges like people's resistance to new ideas and innovations while some members default on loans. Members testified that they have been able to invest in profit generating activities while $86 \%$ of the respondents strongly agreed that CBS PEWOSA performed better than other development projects in the study area. However, the findings revealed that the approach taken by CBS PEWOSA in promoting good farming practices has a lot to desire.

The third research question was to compare the use of various CBS radio edutainment programmes in the improvement of education and exchange of ideas among members of PEWOSA. Findings indicated that edutainment programmes on CBS radio have played a very big role in the improvement of education and exchange of ideas among its listeners. Manyozo, (2012) argues that there is need to use educational 
entertainment in order to educate audiences and therefore influence change. This manifests itself through the participatory methodology of identifying people, where group members through constant interactions create the high-level ownership of the project outcomes. Tufte, (2001) states that theories of participation, social mobilization and advocacy, can all contribute to a better understanding of the impact that communication can have upon its audiences. Through the CBS PEWOSA trade fair, all CBS PEWOSA members are encouraged to attend seminars during the trade shows where facilitators are carefully selected basing on their education background, experience and knowledge on a particular theme. This enables members to gain new knowledge and skills, learn new ideas and innovations to improve on their work. This is in line with the views of Day, (2019) who argues that radio has become an important medium for development and social change, giving communities a platform for communicating about local issues, news and challenges that directly affect their daily lives.

The study also established that homogenous groups of women and men including the youth choose to collectively undertake an economic activity suiting their skills and resources, supplemented by CBS radio matching grants. These work through a Community Managed Micro Finance (CMMF), with an intention of finding a solution to a common problem. Problems range from livelihood generation, food security, vocational skills training and other cross cutting issues like environment, health, education and gender issues with a degree of self-sufficiency. This is in agreement with Fombad \& Jiyane, (2019) who stated that radio stations provide a mechanism for facilitating individuals, groups and communities to tell their own diverse stories, to share experiences, and also to become active creators of and contributors to media. It is important to note that radio is effective in improving the sharing of information among communities. This manifests itself through social cohesion, creation of new friends and forming of groups as expressed by CBS PEWOSA members in the study.

In one of the focused group discussions in Maya Parish, a respondent praised CBS FM on the role it had played in solving her marital challenges;

Through the Emboozi y'amaka programme (Marital Challenges and Solutions programme), the presenter educates us so well; it has brought peace to our families. Most men who were misbehaving have changed from bad to good as result of listening to CBS Radio. The programme gives us advice and how to live a happy life together at home and in the community. As parents we have a responsibility and CBS Radio keeps reminding us the adults [about] our roles (Interview with Nassonko Magdalene, Maya, 2019).

According to the study findings, CBS radio programmes had educated members on new issues in society. The radio has enabled them to create a new network of good friends, and have been able to access viable markets for their products and services. Curran, (2002) argues that the media not only help audiences to know about the world but also to make sense of it. CBS PEWOSA members have been equipped with skills of improving the quality of their products. These include participatory training methods, CMMF formation and strengthening, book keeping and leadership skills. However, members complained that they rarely give feedback about the project even when they have issues that need to be solved; they only meet their group leaders. In one of the focus group discussions in Buddo parish, a member raised a concern;

We are rarely given an opportunity to evaluate the progress of our project. And whenever we meet the project supervisors, they do not have time to listen to all the problems that we have because of the limited time each group is given. If this can be solved, we shall continue to encourage our friends to join because CBS PEWOSA has become part and parcel of our lives (Interview with Mugisha Stephen, Buddo, 2019). 
One of the CBS PEWOSA project staff confirmed this when he cited the challenge of inadequate training staff. The Project Officer promised to increase on training of staff that would be able to reach out to PEWOSA members, advise them and also receive their concerns.

It was also established that CBS radio programmes are able to entertain as well as educate members to improve livelihoods. CBS PEWOSA main intervention themes included mind-set change, financial empowerment, and leadership development, it also involved investments promotion, savings and credit promotion; group synergies, vision building and goal setting. These took communal approach to societal challenges and interdependence as key pillars to the development ladder.

\section{Conclusions}

The activities of CBS PEWOSA as a project have promoted the economic activities of its members in Nsangi and other areas. It has promoted SMEs development through the CMMF groups. The project has provided a forum for its members to reach out to the larger population by participating in the CBS Trade Fairs at very affordable fees. These are also given a business promotion segment on CBS radio to talk about their businesses and services. Business owners said they use the radio and trade fair to advertise their goods and services leading to increased sales and revenue. Many CBS PEWOSA members in the focused group discussions confirmed that they are in a position of saving and borrowing money for investment, have become self-reliant and are able to educate their children. They have acquired capital for their businesses, others have started their own businesses and have become employers. The approach employed by the managers of the project assists the internal functioning of these groups and its members. This is essential because it encourages broader participation of citizens in society. It also facilitates the role in which citizens reinterpret their social experiences, promote self-sufficiency and sustainable community development. Mobilising people into groups for social change is one of the key pillars that has kept CBS PEWOSA project strong. This has enabled members to gain knowledge in savings and credit management, women empowerment, guidance and counselling of the youth plus empowering them to engage in vocational skills. This has improved the quality of life of the members as aligned in the strategic vision and mission of the project.

\section{Recommendations}

CBS radio should ensure that the listeners are involved more in giving feedback on the PEWOSA project as a way of evaluating on issues which affect the performance of their groups. In this case, all members irrespective of their positions should be given a platform to express their views as a measure of improving on CBS PEWOSA activities. This can be done through available social media platforms to reach out to the listeners in terms of receiving feedback, trainings and sending messages. This will help in improving performance and awareness of CBS PEWOSA project in the districts of operation.

It is also important for the management of CBS radio to reconsider increasing on the time allocated to development programmes since majority of the respondents $(66.7 \%)$ were not satisfied with what was allotted. There is also a need to engage more on wider sensitization of the public about the activities of CBS POWESA in order to avoid the fears about the project. Continuous literacy programmes can be of help to curb the illiteracy levels that prevent some members from joining. It is important to note that routine trainings for the project are vital for the continuous instilling of skills for the sustainability of the project interventions. With the new groups coming on board, it calls for more trainers. It is also important to strengthen the financial controls in order to curb the organized fraud by some group members.

Although radio is the most popular mass media avenue, programs about agriculture are executed with little participation from the farmers and extension agents. Based on the findings, the researcher recommends that CBS radio through its PEWOSA project should invest in innovative and participatory approaches to agriculture programming for livelihood improvement. This would attract listenership and an increased level of awareness on the benefits of engaging in agriculture. A lot more should be done 
through CBS radio in creating awareness on the best farming practices for the PEWOSA groups. The positive outcome from improved farming will boost income levels of the group members since agriculture is the backbone of Uganda.

CBS radio through its PEWOSA project still has a lot of work to do especially when it comes to nurturing the so many blossoming cottage industries because the individual members or groups have not yet done well in their businesses and have little money saved up to make big time investments. Most members have no previous experience in owning, or running a business or even sales. This will require a lot of resources in terms of training, capital and support from within the members or groups and the project officers to ensure its sustainability.

Given the illiteracy levels of most members, a lot of attention should be put into workshops and trainings to ensure that those who are already engaged in the project fully understand the current marketing business models like advertising and promotion for them to attract more customers. It is also important that the benefits members have obtained are sustained to ensure improvement of livelihoods.

CBS PEWOSA members' lives will improve even the more if the strategic goals and objectives of the project continue to be implemented and monitored using CBS radio as a change agent, to cause sustainable development. Emphasis can be put on empowerment of members to improve food security, institutional capacity and creating market linkages through the CBS PEWOSA Trade Fairs and SACCOs.

\section{References}

Anderson, G \& Elliott, D 2007, The role and impact of radio in reforming the rural business environment in Africa, Swiss Agency for Development and Cooperation (SDC), Employment and In-come

Division. http://www.deza.admin.ch/ressources/resource

Asemah, E S 2011, Mass Media in the Contemporary Society, Jos: University Press.

Baird, C H and Parasnis, G 2011, From Social Media to Social Customer Relationship Management, Strategy \& Leadership, Vol. 39, no. 5, pp. 30-37

CBS FM radio Strategic Plan, 2010 - 2014.

CBS PEWOSA Monitoring and Evaluation database, 2017.

CBS PEWOSA Project Write UP, 2009.

Chambers, R and Conway, G 1991. Sustainable rural livelihoods: Practical concepts for the $21^{\text {st }}$ Century, Institute of Development Studies, UK.

Chapota, R Fatch, P \& Mthinda, C 2014, 'The Role of Radio in Agricultural Extension and Advisory Services, Experiences and Lessons from Farm Radio Programming in Malawi

Curran, J and Gurevitch, M (eds) 2000, Mass media and Society, 3rd Edition, Edward Arnold: London.

Curran, J P 2002, Media and Power, London: Routledge.

Day, R 2019, 'BBC Media Action Radio for Development, Exploring maternal health programs with a gender and development lens in Ethiopia

Dhanraj, A P 2015, A Voice for the Voiceless: The Role of Community Radio in the Development of the Rural Poor, Walchand Institute of Arts and Science Solapur, Maharashtra, India.

Fombad, M C \& Jiyane, G V 2019, 'The role of community radios in information dissemination to rural women in South Africa', Journal of Librarianship and Information Science, Vol. 51, no. 1, pp. 47-58.

Girard, B 2003, 'The One to Watch: Radio New ICTs and Interactivity FES: Geneva and FAO: Rome

Guenthner, J F \& Swan, B G 2011, 'Extension learners' use of electronic technology', Journal of Extension, Vol. 49, no. 1, pp. 1-9.

Gumucio D A 2001, Making waves: Stories of participatory Communication for Social Change.

Rockefeller Foundation. New York, https://dx.doi.org/10.4135/9781849209342.n1

Manyozo, L 2012, Media, Communication and development London: SAGE. 
McQuail, D 1987, Mass communication theory: An introduction, 2nd edition, Thousand Oaks, CA, US: Sage Publications, Inc.

Myers, M 2009, 'Radio and Development in Africa, A Concept Paper prepared for the International Development Research Centre (IDRC) of Canada

Nabusoba, T 2014, 'The impact of radio agricultural programmes on small scale farmers, ' The case of "Mali shambani" programme on KBC radio Taifa, Nigeria, Research on Humanities and Social Sciences.

Nora, C Quebral 1975, Development Communication; Where Does It Stand Today, Media Asia, Vol. 2, no. 4, p. 197-202.

Saidou, D 2002, Radio Broadcasting and New Information and Communication Technologies: Uses, Challenges and Prospects, United Nations Research Institute for Social Development (UNRISD), Geneva, Switzerland.

Seidu, A, Andani, A \& Abdul-Malik, A 2011, 'The Role of Community Radio in Livelihood Improvement,' The Case of Simli Radio, Field Actions Science Reports [Online], Vol. 5 http://journals.openedition.org/factsreports/869.

Toru, Y 2001, 'Approach to Poverty Reduction in Developing Countries and Japan's Contribution.

Tufte, T 2001, 'Entertainment-education and participation', Journal of International Communication, Vol. 7, no. 2, pp. 25-50.

Turow, J 2016, Media Today: Mass Communication in a converging world. http://en.wikipedia. Org/wiki/Smash (The Offspring album)

UCC Report, 2015, Uganda Communications Commission Radio Spectrum Management Guidelines

Uganda Demographics Profile, 2017

Velentzas, M B 2014, Communication, Public Relations \& Advertisement 